\title{
Phonetic bases of sound symbolism: A review
}

\author{
Shigeto Kawahara (Keio University) \\ 2-15-45, Mita, Minato-ku, Tokyo, Japan \\ $+81-3-5427-1595$ \\ kawahara@icl.keio.ac.jp
}

\begin{abstract}
While the relationships between sounds and meanings are generally arbitrary in human languages, we do observe cases in which systematic correspondences hold between sounds and meanings, at least as stochastic tendencies. When such systematic sound-meaning relationships appear to be modulated by iconicity, we refer to these relationships as "sound symbolism," although defining precisely what it means for a sound to be iconic of its meaning can be difficult. Nevertheless, in many cases, systematic associations between particular meanings and particular sounds seem to make phonetic sense, i.e., sound symbolic meanings appear to have their roots in the articulatory and/or acoustic properties of sounds under question. This paper reviews these sound symbolic patterns together with their phonetic underpinnings, both in terms of their articulatory and acoustic characteristics. While the aim of this review is not to establish a new theory of sound symbolism, two conclusions nevertheless emerge from the survey: (1) phonetic and phonological considerations do seem to offer insights into the patterning of systematic sound-meaning correspondences that are recurrently found in natural languages and (2) we need to take both articulatory and acoustics factors into account when we consider the phonetic bases of sound symbolism. It is hoped that this review can serve as a useful guide for all researchers who work on sound symbolism.
\end{abstract}




\section{Contents}

$\begin{array}{lll}1 & \text { Introduction } & 3\end{array}$

$1.1 \quad$ Phonetic bases of sound symbolism . . . . . . . . . . . . . . . . 3

1.2 Articulation vs. acoustics? . . . . . . . . . . . . . . . . . 5

1.3 Historical precedents . . . . . . . . . . . . . . . . . 6

\begin{tabular}{|lll}
\hline 2 & Preliminary: the Frequency Code & 7
\end{tabular}

3 Vowels: size-related sound symbolism 9

3.1 High vowels are smaller than low vowels . . . . . . . . . . . . . . . . . . . . . . . 9

3.1 .1 Observation . . . . . . . . . . . . . . . . . . 9

3.1 .2 Articulatory explanation . . . . . . . . . . . . . . . . . . . . . . . . . . . . . .

3.1 .3 Acoustic explanation . . . . . . . . . . . . . . . . . 11

3.2 Front vowels are smaller than back vowels . . . . . . . . . . . . . . . . . . . 12

3.2 .1 Observation . . . . . . . . . . . . . . . . . . 12

3.2 .2 Articulatory explanation . . . . . . . . . . . . . . 13

3.2.3 Acoustic explanation . . . . . . . . . . . . . . . . . 13

3.3 H-tones are small . . . . . . . . . . . . . . . . . . . . . . . . . . 14

3.3 .1 Observation . . . . . . . . . . . . . . . . . . . . 14

3.3 .2 Articulatory explanation . . . . . . . . . . . . . 15

3.3 .3 Acoustic explanation . . . . . . . . . . . . . . . 15

4 Vowels: non-size-related sound symbolism 15

4.1 Rounded vowels are round . . . . . . . . . . . . . . . . . . . 15

4.1 .1 Observation . . . . . . . . . . . . . . . . . . 15

4.1 .2 Articulatory explanation . . . . . . . . . . . . . . . . . . . . . . . . . . . . . 16

4.1.3 Acoustic explanation . . . . . . . . . . . . . . . . . . 16

$4.2[\mathrm{a}]$ is red and $[\mathrm{i}]$ is yellow/green $\ldots \ldots \ldots \ldots \ldots$

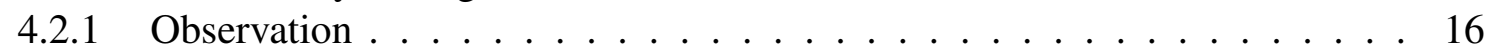

4.2 .2 Articulatory explanation . . . . . . . . . . . . . . . . . . . . . . . . . . . . . . .

$4.2 .3 \quad$ Acoustic explanation . . . . . . . . . . . . . . . . . . 17

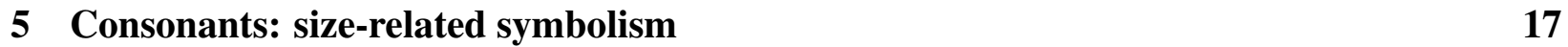

5.1 Palatal consonants are small . . . . . . . . . . . . . . . . . 17

5.1 .1 Observation . . . . . . . . . . . . . . . . 17

5.1 .2 Articulatory explanation . . . . . . . . . . . . . . 17

$5.1 .3 \quad$ Acoustic explanation . . . . . . . . . . . . . . . . . . . . . . . . . . . . . . . . . 18

5.2 Voiced obstruents are large . . . . . . . . . . . . . . . . . . . . . . 18

5.2 .1 Observation . . . . . . . . . . . . . . . . . . 18

$5.2 .2 \quad$ Articulatory explanation . . . . . . . . . . . . . . . . . . . . . . . . . . . . . . .

$5.2 .3 \quad$ Acoustic explanation . . . . . . . . . . . . . . . . . . . . . . . . . . . . . . . . . . .

5.3 Voiceless fricatives are small . . . . . . . . . . . . . . . . . 22

5.3 .1 Observation . . . . . . . . . . . . . . . . . . . . . . . . . . . . . . . . 22

5.3 .2 Articulatory explanation . . . . . . . . . . . . . . . . . . . . 22

5.3 .3 Acoustic explanation . . . . . . . . . . . . . . . . 23 


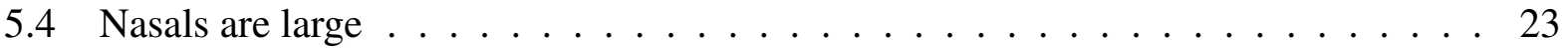

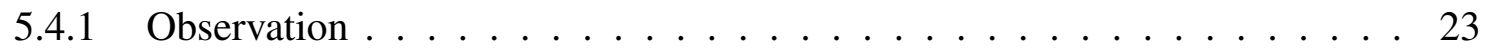

5.4 .2 Articulatory explanation . . . . . . . . . . . . . . 24

$5.4 .3 \quad$ Acoustic explanation . . . . . . . . . . . . . . . . . 24

6 Consonants: non-size-related symbolism

6.1 Voiceless obstruents are angular, voiced consonants are round . . . . . . . . . . . 25

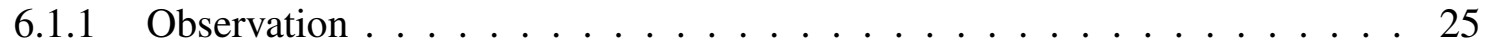

6.1 .2 Articulatory explanation . . . . . . . . . . . . . . . . . . . . . . . . . . . 25

6.1 .3 Acoustic explanation . . . . . . . . . . . . . . . . . . . . . . . . . . . . . . 25

6.2 Labial consonants are baby-like . . . . . . . . . . . . . . . . . 27

6.2 .1 Observation . . . . . . . . . . . . . . . . 27

6.2 .2 Articulatory explanation . . . . . . . . . . . . . . . . . . . . . . . . . . . . . . .

6.2.3 Acoustic explanation . . . . . . . . . . . . . . . . . . 27

6.3 Labial consonants are round . . . . . . . . . . . . . . . . . . . . . . 28

6.3 .1 Observation . . . . . . . . . . . . . . . . . . 28

6.3 .2 Articulatory explanation . . . . . . . . . . . . . 28

6.3 .3 Acoustic explanation . . . . . . . . . . . . . . . . 28

6.4 Nasals=breast . . . . . . . . . . . . . . . . . . . 28

6.4 .1 Observation . . . . . . . . . . . . . . . . . 28

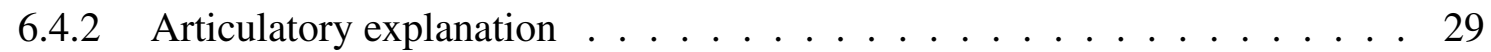

$6.4 .3 \quad$ Acoustic explanation . . . . . . . . . . . . . . . . . . . . . 29

6.5 Sibilants=fly . . . . . . . . . . . . . . . . . . . . . 29

6.5 .1 Observation . . . . . . . . . . . . . . . . . . . . . 29

6.5 .2 Articulatory explanation . . . . . . . . . . . . . . . . . . . . . . . . . . . . . . . . . . . . .

6.5 .3 Acoustic explanation . . . . . . . . . . . . . . . . 30

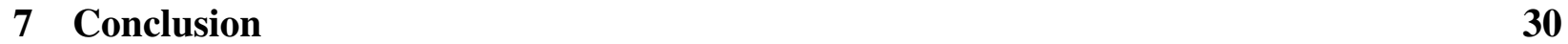

\section{Introduction}

\subsection{Phonetic bases of sound symbolism}

While it had been dominantly assumed in most modern theories of linguistics that the relationships between sounds and meanings are generally arbitrary (Saussure 1916), an increasing number of studies have shown that there can be systematic associations between sounds and meanings. Among such patterns of systematicity, there are cases in which systematic relationships appear to hold because of the iconicity between sounds and meanings, in which case we refer to these associations as "sound symbolism" (Dingemanse et al. 2015; Sidhu and Pexman 2018). This notion 
of iconicity, however, can be elusive, and it is difficult to pin down precisely what it means for a sound to be iconic of its meaning.$^{1}$ From the viewpoint of general phonetic science, however, many cases of sound symbolic meanings make phonetic sense. That is, particular meanings of particular sounds seem to have their roots in the articulatory and/or acoustic properties of sounds under question..$^{2}$ The goal of this article is to give an overview of these articulatory and acoustic bases of sound-meaning connections. I hope that this document can be used as a "pocket guide" for all researchers interested in sound symbolism, especially for those who are not necessarily interested in phonetic research per se.

The general idea that research on sound symbolism can benefit from phonetic considerations largely owes to John Ohala, who in a series of papers proposed to investigate sound symbolic patterns as a part of phonetic inquiry (e.g. Ohala 1983b, 1984, 1994). To borrow the words of Keith Johnson, "[Ohala] was deeply interested in the ethology of sound symbolism. He felt that sound symbolism was an understudied field where most work lacked scientific rigor. His goal was to propose 'a unifying, ethologically based and phonetically plausible theory of aspects of sound symbolism"” (Johnson 2020: 453). As reviewed in detail below, Ohala argues that some sound symbolic patterns have their roots in phonetic properties of the sounds at issue. To the extent that Ohala's assertion is on the right track, it would imply that taking into account phonetic considerations is important for any theory of sound symbolism.

Sound symbolism is not only relevant for phonetic research, as Ohala envisioned, but can also be relevant for theoretical phonology. From the perspective of theoretical phonology, we can say that sound symbolic patterns are demonstrably grounded in the phonetic properties of sounds, just like some phonological patterns which are grounded in phonetic considerations (e.g. Archangeli and Pulleyblank 1994; Hayes et al. 2004). As such, Kawahara (2020a) argues that studying sound symbolic patterns can be of interest not only for phoneticians, but also for formal phonologists, for

\footnotetext{
${ }^{1}$ An oft used definition of iconicity is "meaning what it sounds like" (e.g. Perlman and Lupyan 2018), which makes intuitive sense, but I find it hard to evaluate this criterion on an objective basis. I hasten to add that the goal of this paper is not to challenge this notion of iconicity at all (for a recent defense of this concept, see Winter and Perlman 2021a); instead, my goal is to explicate this potentially subjective notion of iconicity from phonetic perspectives.

${ }^{2} \mathrm{~A}$ clear case of systematicity that does not seem to have a phonetic basis, for example, is English [gl-] sequence, which is often associated with the notion of light (Bergen|2004). I suspect that there is no phonetic sense in which the [gl-] sequence emits light. Such cases instantiate systematic associations that are not sound symbolic.
} 
whom the relationships between phonetic considerations and phonological patterns have always been an important theoretical issue (see Zsiga|2020 for a review) ${ }^{3}$ In addition, a few recent studies have demonstrated that phonological factors may influence sound symbolic patterns (Dingemanse and Thompson 2020; Jang 2021), which implies that there should be more communication between the research on sound symbolism on the one hand, and phonetics/phonology research on the other. This paper offers an attempt to facilitate this communication.

To illustrate what will be reviewed in this paper, one of the best known cases of sound symbolism is the observation that [a] is often judged to be larger than [i] by speakers of various languages (e.g. Sapir 1929; see below for more). This sound symbolic pattern holds arguably because the oral aperture is more open for [a] than for [i] (Sapir 1929). Alternatively, the acoustic properties of [a] may be such that they invoke large images. This paper aims to put together the list of this sort of sound symbolic patterns that make phonetic sense, and clarify the articulatory and/or phonetic mechanisms that may underlie these sound symbolic patterns. ${ }^{4}$

\subsection{Articulation vs. acoustics?}

A question that one may address in this context is whether either articulation or acoustics alone would suffice. This question is interesting to ask, because we find a similar question addressed in other related research fields. For example, in the formal phonology literature, one continuing debate is whether phonological representations should be based on articulation or acoustics. The dominant view in the generative phonology tradition is that phonological representations (a.k.a. "distinctive features") are (mostly) based on articulation (e.g. Chomsky and Halle 1968), but there are proposals to incorporate auditory representations in phonology (e.g. Flemming 1995). There is, on the other hand, a general theory of phonology, known as Articulatory Phonology, which posits

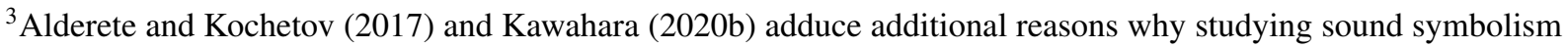
can be interesting and important for formal phonologists.

${ }^{4}$ One related question which I do not delve into in this paper due to space limitation is the issue of universality of sound symbolism. To the extent that sound symbolism is grounded in phonetic properties, and to the extent that speakers of different languages share the same articulators and communicate under comparable physical settings, it would not be surprising if sound symbolic associations are observed universally across languages. For the universality and language-specificity of sound symbolic patterns, see, for instance, Bremner et al. (2013), Iwasaki et al. (2007), Saji et al. (2019) and Styles and Gawne (2017).
} 
articulatory gestures as phonological primitives (Browman and Goldstein 1986 et seq).

Similarly, in phonetics, researchers debate whether the object of speech perception should be defined in terms of articulation, as in Motor Theory (Liberman and Mattingly 1985) and Direct Realism (Fowler 1986), or in terms of (psycho)acoustic properties, as in the Auditorist Theory of speech perception (Diehl et al. 2004). It has also long been debated whether speakers' articulatory goals should be defined in terms of articulatory targets or auditory targets (e.g. Browman and Goldstein 1986 vs. Houde and Jordan 2002). In short, whether various aspects of our speech behavior are regulated by articulatory considerations or (psycho)acoustic considerations has long been debated in the literature. It is interesting that the same issue can be addressed as we study sound symbolism, and it is helpful to have this larger picture in mind, even when our empirical targets are specifically about sound symbolic connections.

In these debates, researchers seem to try to choose one over the other (i.e. it is either articulation or acoustics, but not both), whereas in the literature on sound symbolism, researchers seem to be more willing to accept both articulatory and acoustic explanations.5 The review of the phonetic grounding of sound symbolic patterns presented below suggests that we do indeed need to take both articulatory and acoustic factors into account.

\subsection{Historical precedents}

The idea that at least some systematic sound-meaning connections have their roots in their phonetic properties is not at all new, and in fact goes back at least to Plato's Cratylus. There, Socrates entertains various hypotheses regarding why several systematic sound-meaning relationships hold. For example, he suggests that $\rho$ (which was most likely an alveolar trill in Classic Greek) is suited for words that represent movement, because the tongue moves repeatedly to produce this sound. Sapir (1929: 233), a pioneering experimental study on sound symbolism, states that "the symbolic discriminations run encouragingly parallel to the objective ones based on phonetic considerations."

\footnotetext{
${ }^{5}$ In the literature on phonetic grounding of phonological patterns too, researchers are often willing to accept both articulatory and perceptual factors, the two most widely discussed principles being "promoting the ease of articulation" and "signaling phonological contrasts in perceptually salient ways" (see Zsiga|2020 for a review)
} 
Jespersen (1922: 558-559) likewise points out that [i] is considered to be smaller than other vowels, and entertains two possible hypotheses, one based on acoustics and one based on articulation: "[t]he reason why the sound [i] comes to be easily associated with small, and [u, o, a] with bigger things, may be to some extent the high pitch of the vowel...; the perception of the small lip aperture in one case and the more open mouth in the other may have also its share in the rise of the idea."

Thus, the idea that sound symbolic patterns have phonetic bases is old and popular; the goal of the present article is to reconsider this issue of phonetic bases of sound symbolism by summarizing the major findings from recent research on sound symbolism, in light of modern perspective of phonetic sciences.

\section{Preliminary: the Frequency Code}

Before diving into several cases of sound symbolism and their phonetic groundings, it is useful to review the Frequency Code hypothesis proposed by Ohala (1983b, 1984, 1994), because this hypothesis can be relevant for many cases of sound symbolism. This principle in a nutshell suggests that sounds with low frequency energy are judged to be large, and sounds with high frequency energy are judged to be small. This section reviews the physical mechanisms that lie behind the Frequency Code. There are actually two ways in which the Frequency Code can be relevant for sound symbolic patterns.

First, the fundamental frequency of an ideal string is inversely proportional to the length of that string. The equation that expresses this physical principle is given in (1), in which the length of the string $L$ appears in the denominator of the right side of the equation. Put in more plain terms, a shorter vibrator emits a higher sound.

$$
F_{0}=\frac{1}{2 L} \sqrt{\frac{\sigma}{\rho}}
$$

where $F_{0}=$ the fundamental frequency, $L=$ length, $\sigma=$ tension, $\rho=$ density 
This relationship is perhaps easy to understand when we consider musical instruments of different sizes. A big instrument (like a contrabass) produces lower sounds and a small instrument (like a violin) produces higher sounds. This relationship is also easy to understand when we compare adults' voices and children's voices. Children have smaller (i.e. shorter) vocal folds, which tend to emit higher sounds (although, please note that vocal fold size is not the only factor that determines the pitch of our voices).

Next let us turn to the relationship between the size of a resonator and its resonating frequency. In many cases, it is convenient to approximate the vocal tract configuration as consisting of several tubes (e.g. Stevens 1989). The frequency of a wave that resonates in a tube depends on several factors, including whether the two ends of the tube are closed or open. A tube that is commonly used to simulate a vocal tract configuration has one closed end and one open end, as schematically illustrated in Figure 1 .

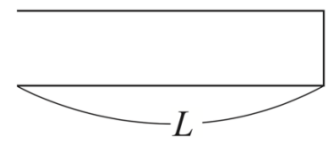

Figure 1: A schematic illustration of a tube with one closed end and one open end.

Given a tube of this shape whose length is $L$, the lowest resonating frequency $F$ can be approximated by Equation (2).

$$
F=\frac{c}{4 L}
$$

where $F=$ resonating frequency, $L=$ length of the resonating cavity and $c=$ the speed of sound

In fact, there can be-and indeed are-multiple waves that resonate in a tube. The frequencies of these resonating waves can be expressed in one general formula, given in (3). Equation (2) is a 


\footnotetext{
${ }^{6}$ Since the literature on sound symbolism is so vast now, I do not even attempt to be comprehensive when describing each sound symbolic pattern. See e.g. Akita (2010) and Westbury et al. (2018) for impressive reviews of the relevant work.
}

$$
F_{n}=\frac{c}{\frac{4}{2 n-1} L}
$$

where $F_{n}$ is the frequency of the $n$-th resonating wave.

Importantly, all the resonating frequencies are inversely proportional to the length of the resonating tube. More plainly put, resonation with higher frequency energy is emitted from a shorter resonating chamber. We can "experimentally" feel this relationship just with a bottle and water. Blow into an empty bottle and hear its resonation; then put some water in the bottle and blow again. The resonation frequency goes up when there is water in the bottle, because the non-filled portion of the bottle gets smaller. We can even feel that the more the bottle is filled, the smaller the resonating chamber becomes, and the higher the resonating frequency gets.

\section{Vowels: size-related sound symbolism}

Let us now examine actual cases of sound symbolism and consider their articulatory and phonetic bases. For the sake of exposition, I start with sound symbolism related to vowels, and then move on to the discussion of consonants. For each pattern, I briefly describe the sound symbolic connection at issue, and discuss possible articulatory and acoustic explanations. ${ }^{6}$

\subsection{High vowels are smaller than low vowels}

\subsubsection{Observation}

Higher vowels tend to be judged as smaller than lower vowels. This observation is exemplified by the very well-known experimental finding by $\operatorname{Sapir}(1929)$ that [a] (=a low vowel) is judged to be 
larger than [i] (=a high vowel). A recent study by Winter and Perlman (2021b) shows that this tendency may generally pertain to size-related adjectives in the entire English lexicon. Experiments using Pokémon characters have shown that [a] tends to be associated with larger, post-evolution characters whereas [i] tends to be associated with smaller, pre-evolution characters by speakers of various languages, including English, Japanese and Brazilian Portuguese (Godoy et al. 2020, Kawahara and Moore 2021; Kumagai and Kawahara 2019). Ultan (1978) and Blasi et al. (2016) show based on typological surveys that [i] is often used to express diminutive meanings and smallness.

This often-discussed comparison between [a] and [i], however, conflates the difference in vowel height with the difference in vowel backness, because [a] is a low back vowel and [i] is a high front vowel. The experiment by Newman (1933) shows that English speakers judge [i] to be smaller than [e]. Since [i] and [e] can be both classified as front vowels, this result suggests the vowel height indeed can affect size ratings. Shinohara and Kawahara (2016) report a rating study with Chinese, English, Japanese and Korean speakers, which shows a general effect of vowel height on size judgments.

\subsubsection{Articulatory explanation}

The oral aperture - how widely open our mouth is during articulation-is wider for low vowels than high vowels. This difference is illustrated in the MRI images presented in Figure 2; the left figure shows the vocal tract configuration for a low vowel, whereas the right figure shows that for a high vowel. The jaw as well as the tongue are much lower during the production of a low vowel than a high vowel, resulting in wider oral aperture. Sapir (1929: 235) resorts to this sort of explanation for his experimental findings: "[i]n the case of $i$ the tongue is high up toward the roof of the mouth and articulates pretty well forward. In other words, the vibrating column of air is passing through a narrow resonance chamber. In the case of $a$ the tongue is very considerably lowered in comparison, and also retracted. In other words, the vibrating column of air is now passing through a much wider resonance chamber." 

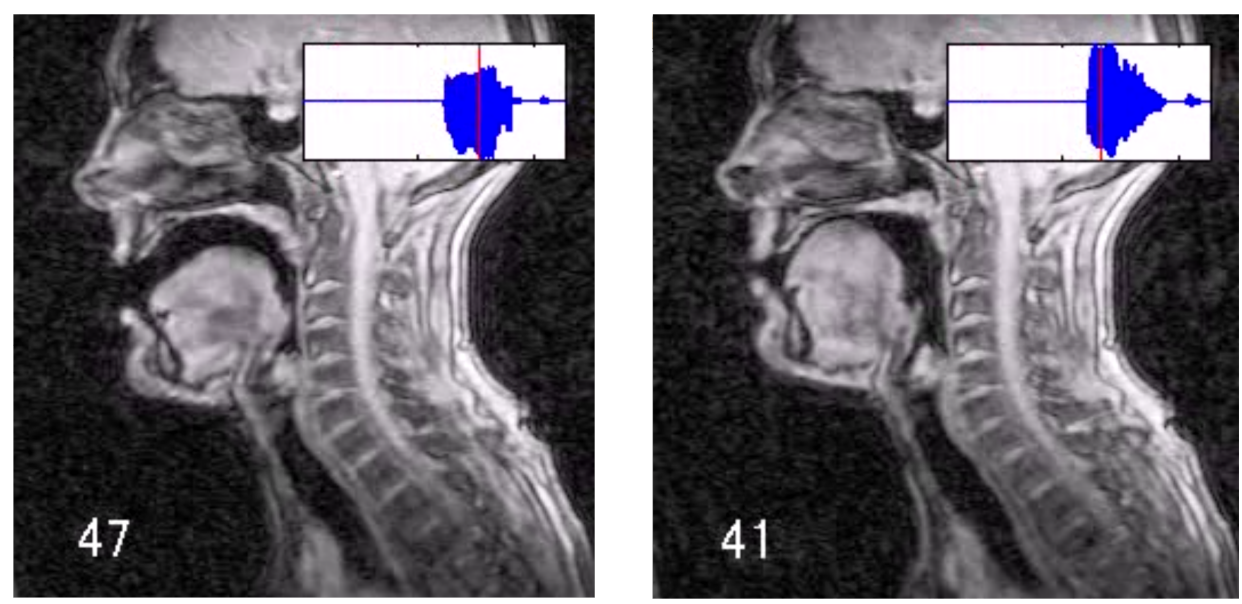

Figure 2: The MRI images of an English speaker producing bat (=left) and beet (=right). The still images were extracted during the production of the vowels.

\subsubsection{Acoustic explanation}

The fundamental frequency $(=\mathrm{F} 0)$ of low vowels is intrinsically lower than that of high vowels (Whalen and Levitt 1995).7 The tongue and the larynx are anatomically connected via the hyoid bone; the raising of the tongue body for high vowels thus raises the larynx as well, which in turn results in higher fundamental frequency. $]^{8}$ Since high vowels have intrinsically higher fundamental frequency, by way of the general correlation between the frequency and the sound source (=Equation (1)), high vowels can be judged to be smaller.

One caution is necessary in interpreting this relationship, however. When speakers generate sounds with higher fundamental frequency, they stretch-rather than shorten-their vocal folds by, among other things, contracting the cricothyroid muscle. This action lengthens the vocal folds, but increases their tension $(=\sigma)$, resulting in higher fundamental frequency (again, see Equation (1)). Therefore, articulatorily speaking, higher fundamental frequency does not necessarily mean

\footnotetext{
${ }^{7}$ The term "fundamental frequency" and "pitch" are often used interchangeably, although to be precise, the former is the acoustic measure, whereas the latter is the perceptual measure.

${ }^{8} \mathrm{We}$ can feel the relationship between the larynx height and fundamental frequency by placing our fingers on our Adam's Apple (or somewhere near it) and producing voices with different pitch. We can feel that when we produce voices with higher pitch, our larynx goes up. A nice demonstration of this relationship can also be viewed at https://youtu.be/vkZ1XZTbo_E.
} 
shorter vocal folds; it instead often means longer vocal folds. In other words, when speakers associate vowels with higher fundamental frequency with small images, they may not be directly referring to the length of vocal folds per se. They probably are instead referring to an abstract relationship between fundamental frequency and the size of the sound source.

Another general concern regarding the acoustic explanation discussed here is why the first formant frequency (F1) does not dictate the size-related sound symbolic pattern, at least not as much as fundamental frequency or second formant frequency (see Knoeferle et al. 2017). The lower the vowels, the higher the first formant frequency (for which, see Figure 4 below). The correlation between frequency and the size of the resonator predicts that lower vowels should be judged smaller, contrary to what is generally observed (though see Diffloth 1994). To the best of my knowledge, why first formant frequency does not trigger size-related sound symbolic patterns according to the Frequency Code has remained a mystery to date, especially given that first formant frequency often distributes around the frequency ranges to which our auditory system is most sensitive.

Another possible contributing factor that makes higher vowels sound smaller may be because high vowels are acoustically less intense than low vowels, because more energy is trapped in the oral cavity (although this correlation is not always straightforwardly observed, see Parker 2008). It makes sense from the iconicity point of view that quieter sounds are associated with small sound source.

\subsection{Front vowels are smaller than back vowels}

\subsubsection{Observation}

The sound symbolic studies on the front/back vowel contrast is one of the most actively studied topics in the literature (see e.g. Table 1 of Westbury et al.|2018). Front vowels tend to be judged to be smaller than back vowels. Sapir]s (1929) finding that [a] (=a back vowel) is judged to be larger than [i] (=a front vowel) is compatible with this generalization. Newman's (1933) followup experiment shows that back vowels are generally judged to be larger than front vowels by 
English speakers. Shinohara and Kawahara (2016) identify a similar pattern for speakers of other languages. Berlin (2006) argues that this effect is observed in ethonozoological nomenclature in various languages, in which front vowels tend to be used for smaller animals (such as squirrel) and back vowels tend to be used for large animals (such as tapir). Coulter and Coulter (2010) show that in a price discount judgment experiment, English speakers treat six and three, both with front vowels, as small numbers, whereas they treat two with a back vowel as a large number.

\subsubsection{Articulatory explanation}

Front vowels have a smaller resonating cavity in front of the tongue compared to back vowels, as illustrated by the pair of MRI images in Figure 3. The left panel shows the vocal tract configuration of [i] and the right panel shows that of [u]. The lengths of the resonating tubes are shown with red arrows. This difference in the lengths of the resonating chamber can be responsible for the sound symbolic meanings of front and back vowels.
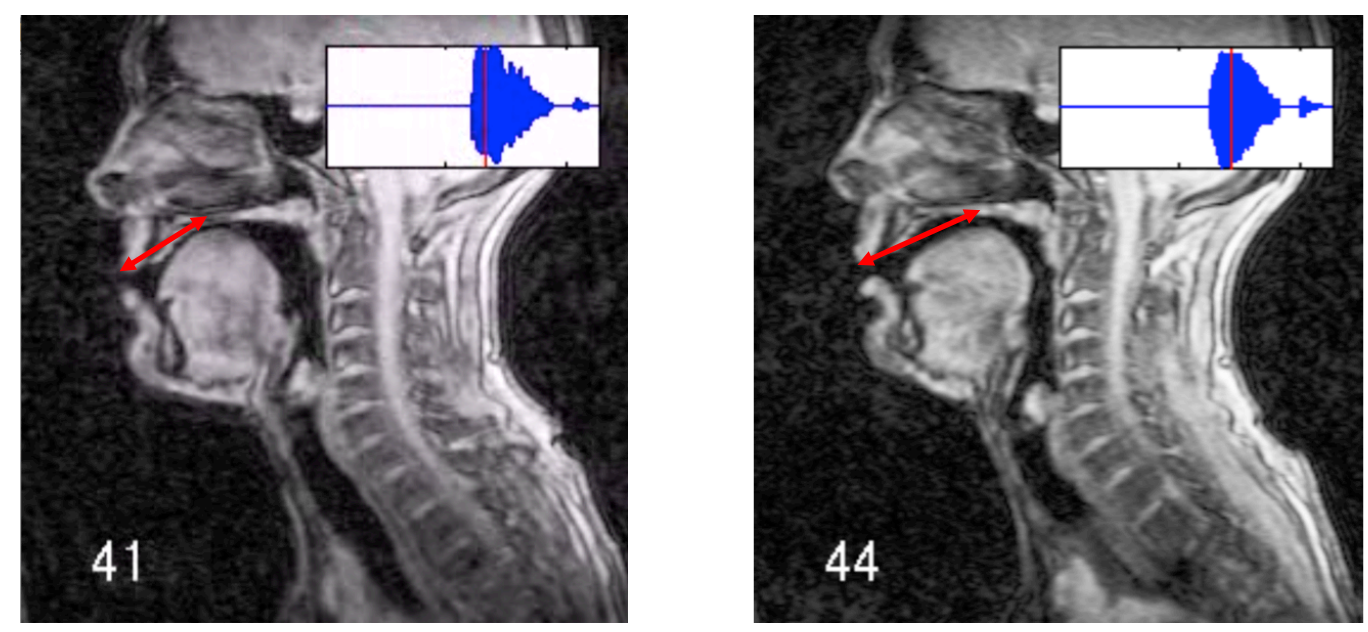

Figure 3: The MRI images of an English speaker producing beet (=left) and boot (=right).

\subsubsection{Acoustic explanation}

Due to the differences in the lengths of the resonating cavity in front of the tongue shown in Figure 3 , the resonating frequency (=second formant) is higher for front vowels than for back vowels. The 
differences in second formant frequency among different vowels are illustrated in the spectrograms in Figure 4. Spectrograms are visual representation of energy distributions of sounds, in which the $\mathrm{y}$-axis represents frequency, and the $\mathrm{x}$-axis represents time. Energy distribution is shown as black lines, where thickness of black lines represent how much energy is present in that frequency region.

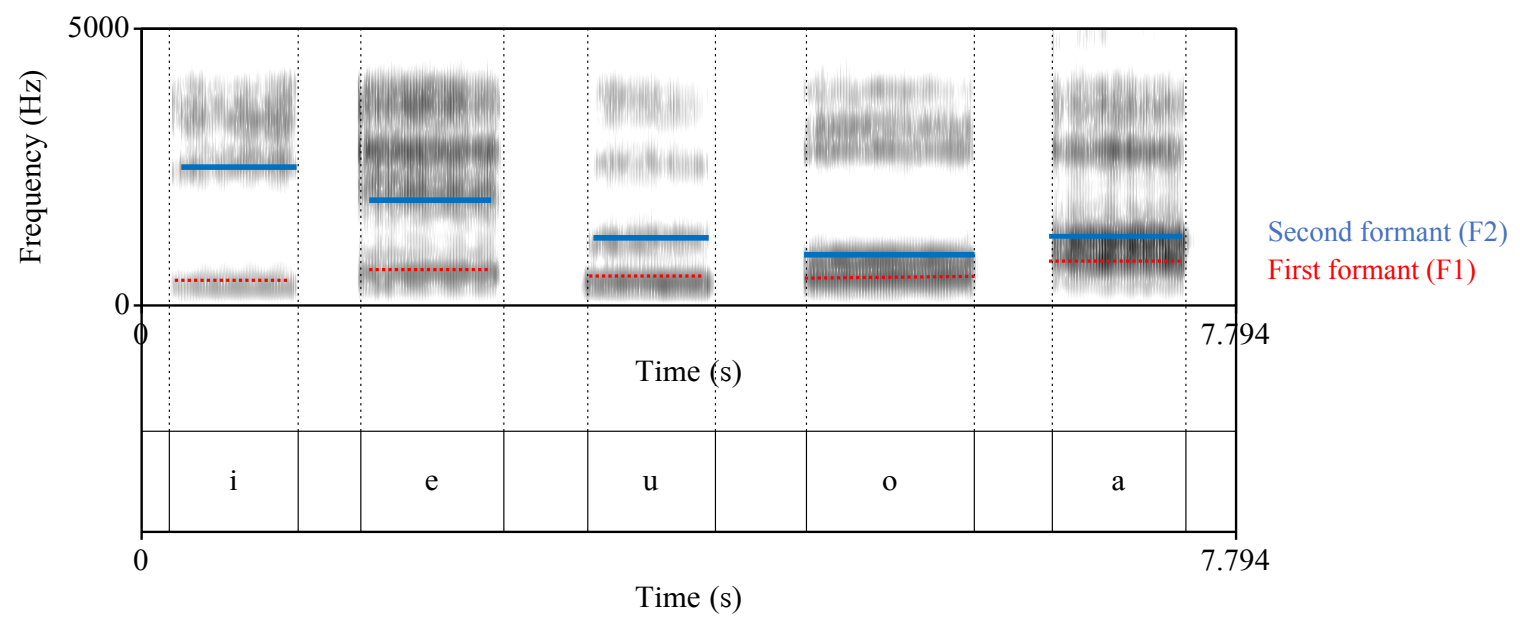

Figure 4: The spectrograms of $[\mathrm{i}],[\mathrm{e}],[\mathrm{u}],[\mathrm{o}]$, and $[\mathrm{a}]$ produced by the author. The bottom lines represent first formant (shown by red dotted lines). The second second lines from the bottom represent second formant (shown by solid blue lines).

We can observe in Figure 4 that the two front vowels ([i] and [e]) generally have higher second formant frequency (solid blue lines) compared to to the three back vowels ([u], [o] and [a]). From Equation (2), listeners can infer that front vowels have smaller resonating chambers than back vowels, resulting in the "front=small" and "back=large" associations.

\subsection{H-tones are small}

\subsubsection{Observation}

In some languages such as Twi, a high tone $(=\mathrm{H}$ tone $)$ can represent something small, whereas a low tone represents something large (Ohala 1983b); e.g. [kàkrá] 'small' vs. [kàkrà] 'large,' where [á] represents a H-toned [a] (see also Lapolla 1994). Gussenhoven (2004) argues that many languages 
use rising intonation (i.e. a $\mathrm{H}$ tone) for interrogative sentences, because one may as well want to sound "small" when seeking for information.

\subsubsection{Articulatory explanation}

To produce $\mathrm{H}$ tones, the cricothyroid muscle is contracted, which stretches the vocal folds. As a result, vocal folds get thinner when producing $\mathrm{H}$ tones, which can be projected onto small images. However, we should bear in mind that vocal folds also get longer as a result of the contraction of the cricothyroid muscle. Thus, as long as we are talking about the "thin-ness" rather than the "length" of vocal folds, the correlation between H tones and smallness makes phonetic sense.

\subsubsection{Acoustic explanation}

This sound symbolic relationship between H-tones and smallness straightforwardly follows from the relationship between the size of a sound source and its fundamental frequency. See Equation (1) — voices with higher frequencies are produced by smaller vibrators.9

\section{Vowels: non-size-related sound symbolism}

\subsection{Rounded vowels are round}

\subsubsection{Observation}

Non-low back vowels such as [u] and [o] are articulatorily rounded-produced with lip protrusion-in English and many other languages. Rounded vowels tend to be associated with round figures, whereas unrounded vowels tend to be associated with angular figures. This effect is observed in the well-known bouba-kiki effect, in which the rounded vowel [u] tends to be associated with a round shape, whereas the unrounded [i] tends to be associated with an angular/pointy

\footnotetext{
${ }^{9}$ John Ohala and I once discussed this issue regarding whether sound symbolic patterns should be derived from articulatory considerations or acoustic considerations $(\$ 1.2)$. He suggested that this association between $\mathrm{H}$ tones and smallness is a good argument for the acoustic-based theory of sound symbolism. I came up with the articulationbased explanation in 3.3 .2 much later after our conversation. I admit, however, that this articulatory explanation is incomplete - it is not clear why listeners attend to the thickness rather than the length of vocal folds.
} 
shape (Ramachandran and Hubbard 2001). A more systematic experiment on this effect with English speakers is reported by D'Onofrio (2014), although the distinction tested in this experiment is a front vs. back distinction, which mostly coincides with a roundedness distinction in English for non-low vowels, since high and mid front vowels are unrounded whereas the back ones are rounded. A recent study by Sidhu et al. (2021) shows that [u] and [ov], both rounded vowels in English, are overrepresented in actual words that are related to roundness in English. Ahlner and Zlatev (2010) report an experiment with Swedish speakers, in which [i] tends to be associated with an angular object, whereas $[\mathrm{u}]$ tends to be associated with a round object.

\subsubsection{Articulatory explanation}

The lip rounding gesture of rounded vowels can be iconically mapped onto round figures. There is a literal sense in which rounded vowels are rounded, because the lips are rounded.

\subsubsection{Acoustic explanation}

To the best of my knowledge, there is nothing in the acoustics of rounded vowels that can be directly related to the notion of roundness. Lip rounding lowers the second formant frequency by lengthening the resonating cavity in front of the tongue, but low second frequency is not, in and of itself, related to round images.

\section{2 [a] is red and [i] is yellow/green}

\subsubsection{Observation}

It has been observed in the studies on color-related sound symbolic patterns that [a] is associated with redness, whereas [i] is associated with yellowness or greenness (Moos et al. 2014; Mok et al. 2019). 


\subsubsection{Articulatory explanation}

I cannot come up with an articulatory explanation why particular vocalic articulations should be associated with particular colors.

\subsubsection{Acoustic explanation}

These associations on the other hand make sense from an acoustic point of view. Physically, red is characterized as low frequency waves whereas yellow/green are characterized as high frequency waves. Recall from Figure 4 that [a] has low second formant frequency, whereas [i] has high second formant frequency, which match well with the frequency profiles of these colors. There is also a report that [i] is associated with brightness and [a] is associated with darkness (Asano and Yokosawa 2010). This observation too makes physical sense, because high frequency waves have higher energy. See Johansson et al. (2020a) and Mok et al. (2019) for extended discussions on color-related sound symbolism and its acoustic bases.

\section{Consonants: size-related symbolism}

\subsection{Palatal consonants are small}

\subsubsection{Observation}

Palatalization, often accompanied by affrication, is a cross-linguistically ofted-used process to express diminutive meanings, and it is frequently found in baby-talk registers across many languages as well (see Alderete and Kochetov 2017 for a typological survey).

\subsubsection{Articulatory explanation}

As far as I know, there is nothing in the articulation of palatal consonants (e.g. [ $]$ ] as in cash or [tf] as in church) that can be related to the notion of smallness or diminutive meanings. However, it has been observed, for example, that Japanese children show extended palatalization patterns in 
their speech (e.g. Li et al. 2011). The diminutive meanings may have its roots in this palatalization pattern that is specifically observed in child speech, e.g. by applying palatalization, adults mimic the child's speech style thereby showing affection and diminutive meanings.

\subsubsection{Acoustic explanation}

Palatal and palatalized consonants raise the second formant of surrounding vowels, as illustrated by the spectrogram in Figure 5, in which the second formants are highlighted with blue lines. We observe that the second format is raised toward [t]], but not toward [p]. We can also compare the burst energy of [p] and [t $\left.\int\right]$ (highlighted by red squares) and observe that the latter has a burst of energy with much higher frequency components. From Equation (2), listeners can thus infer that the sound is generated from a small resonating chamber for a syllable containing a palatal consonant.

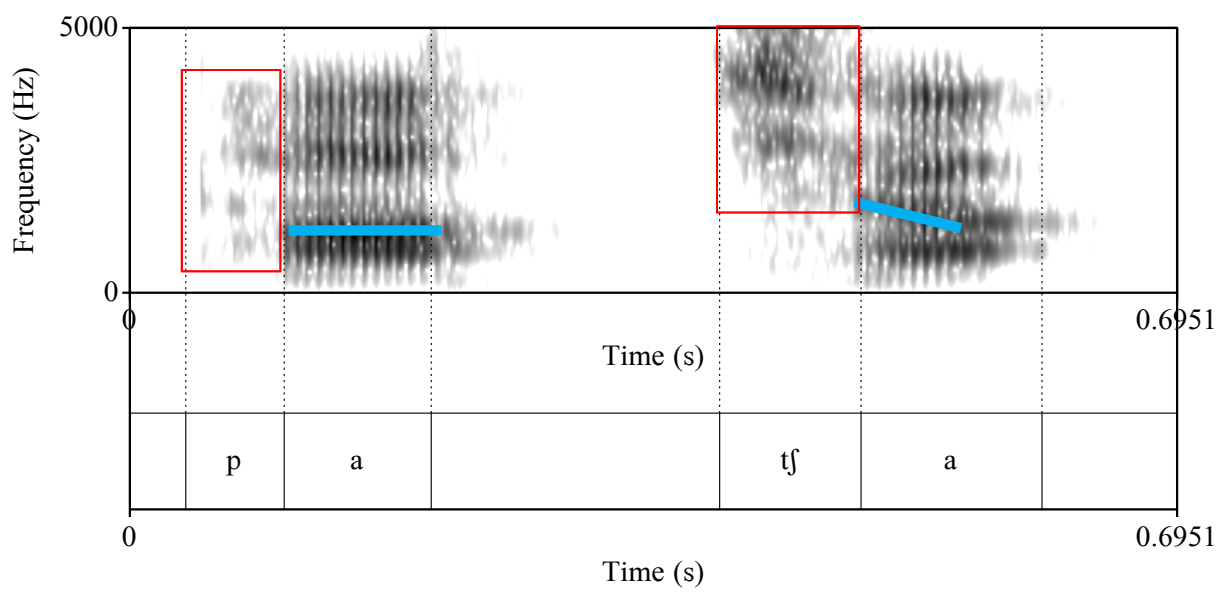

Figure 5: The spectrograms of [pa] and [t $\mathrm{fa}]$

\subsection{Voiced obstruents are large}

\subsubsection{Observation}

Voiced obstruents (e.g. [b, d, g, z]) are judged to be larger than voiceless obstruents (e.g. [p, t, k, s]). This sound symbolic effect was shown for English speakers first by Newman (1933) and 
recently more extensively by Westbury et al. (2018). This observation is very clearly observed in Japanese, especially in its ideophone system (Hamano 1998). For example, koro-koro represents a small rolling rock, whereas goro-goro represents a large rolling rock. Several experiments using Pokémon names show that this correlation between voiced obstruents and large size hold for Japanese speakers (Kawahara and Kumagai 2021), English speakers (Kawahara and Breiss 2021) and Brazilian Portuguese speakers (Godoy et al.2020).

\subsubsection{Articulatory explanation}

The sound symbolic connection between voiced obstruents and largeness can be grounded articulatorily in the expansion of the supralaryngeal cavity necessitated by the aerodynamic requirement that voiced stops present (Ohala 1983a). In order to maintain voicing (=vocal fold vibration), it is necessary that the pressure in the oral cavity is lower than the pressure in the subglottal cavity. However, airflow that is necessary to maintain voicing is trapped in the oral cavity, thereby increasing the pressure in the oral cavity. In order to sustain voicing, speakers make use of Boyle's Law $^{10}$ and expand the oral cavity thereby keeping the pressure in the oral cavity low. This expansion of the oral cavity is visually illustrated by the MRI images of the pharynx region during the production of [s] and [z] (Proctor et al. 2010), which are reproduced here as Figure 6 ,
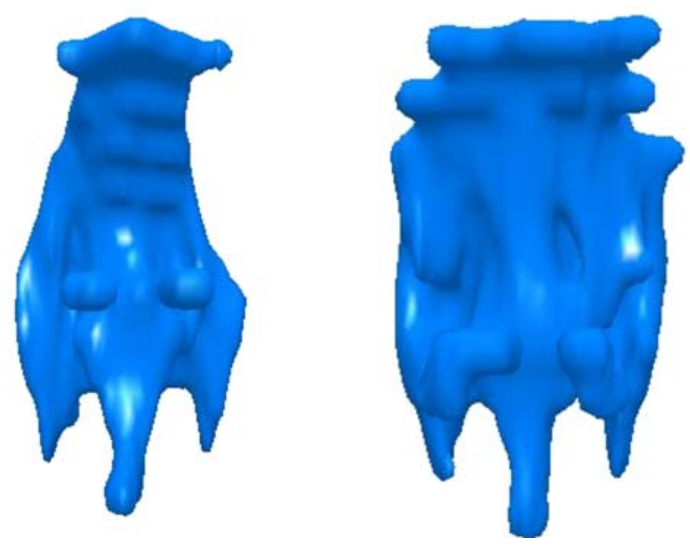

Figure 6: The MRI images of an English speaker producing [isi] (=left) and [izi] (=right).

\footnotetext{
${ }^{10} P \times V=k$; the product of pressure $(P)$ and volume $(V)$ is constant.
} 
As a side note, this articulatory maneuver can be challenging, and therefore, some languages, such as Hawai'ian, avoid using voiced obstruents in favor of voiceless obstruents in their phonemic inventory (Hayes and Steriade 2004, Ohala 1983a). In the literature on sound symbolism in Japanese, voiced obstruents are known to cause negative images (e.g. Hamano 1998), an intuition that English speakers demonstrably share (Shinohara and Kawahara 2009). Some studies entertain the possibility that such negative images may be related to the articulatory difficulties presented by the aerodynamics of voiced obstruents (e.g. Uno et al.2020), although it is not perfectly clear how articulatory challenges are projected onto the general notion of negativeness.

\subsubsection{Acoustic explanation}

One major difference between voiced obstruents and voiceless obstruents is the presence/absence of vocal fold vibration during the consonantal interval. Vocal fold vibration is acoustically realized as low frequency energy, also known as "a voice bar" (Stevens and Blumstein 1981). Figure 7 compares the spectrograms of rapid and rabbit produced by an English speaker. During [b], we observe low frequency energy at the bottom of the spectrogram (shown with a square), which is absent during [p]. In addition, both fundamental frequency and first formant frequency are lower next to voiced obstruents than next to voiceless obstruents (Kingston and Diehl 1994), and the frequency distribution of burst noise is also generally lower for voiced stops than for voiceless stops (Chodroff and Wilson 2014). These low frequency properties of voiced obstruents may lead to the image of largeness because of the relationship between the size of a resonator and its resonating frequency (=Equation 2)). 

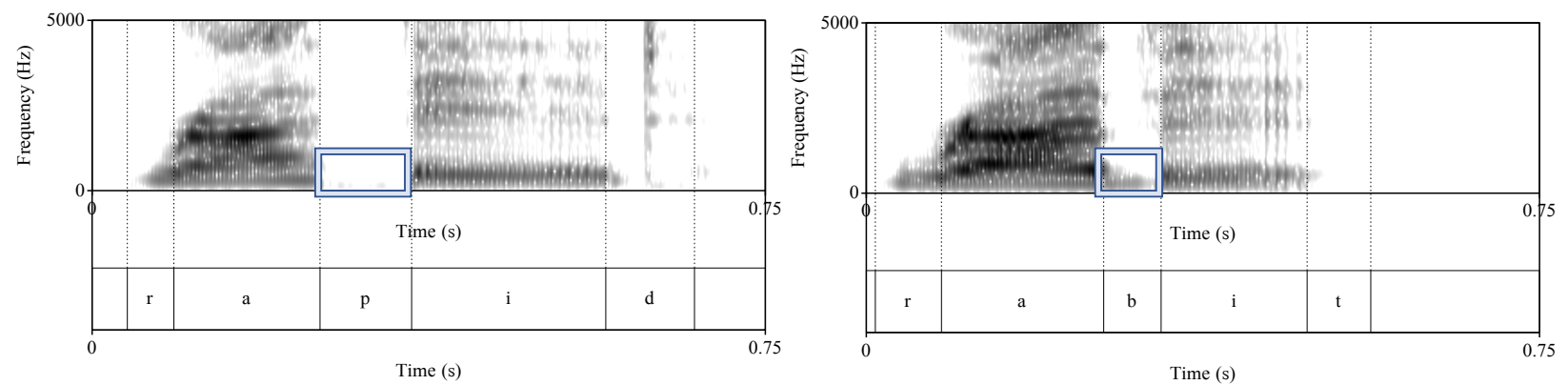

Figure 7: The spectrograms of rapid and rabbit.
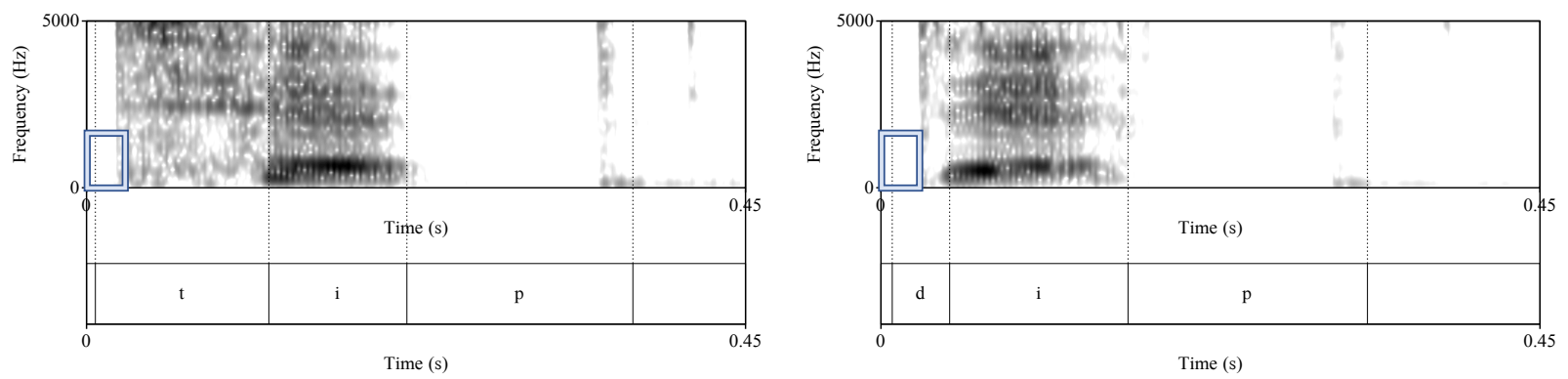

Figure 8: The spectrograms of tip and dip. 


\subsection{Voiceless fricatives are small}

\subsubsection{Observation}

Coulter and Coulter (2010) report an experiment in which English speakers make judgment about price discounts. They find that English speakers behave as if two (with a stop and a back vowel) is "a big number" whereas three and six (with voiceless fricatives and front vowels) are "small numbers." This pattern can be partially attributed to the images of smallness associated with voiceless fricatives (here $[\theta]$ in three and $[\mathrm{s}]$ in six), although a stop/fricative distinction is confounded with a vowel backness distinction in this experiment. Kawahara and Moore (2021) do not find a substantial effect of a stop/fricative distinction in the context of naming large, post-evolution Pokémon characters.

\subsubsection{Articulatory explanation}

The oral aperture is extremely narrow during the production of voiceless fricatives in order to create frication, which is illustrated by the MRI image in Figure 10. To the extent that the degree of oral aperture affects size-related sound symbolism, as it does for vowels (see $\$ 3.1 .2$ ), it does not come as a big surprise if this narrow aperture is projected onto the image of smallness.

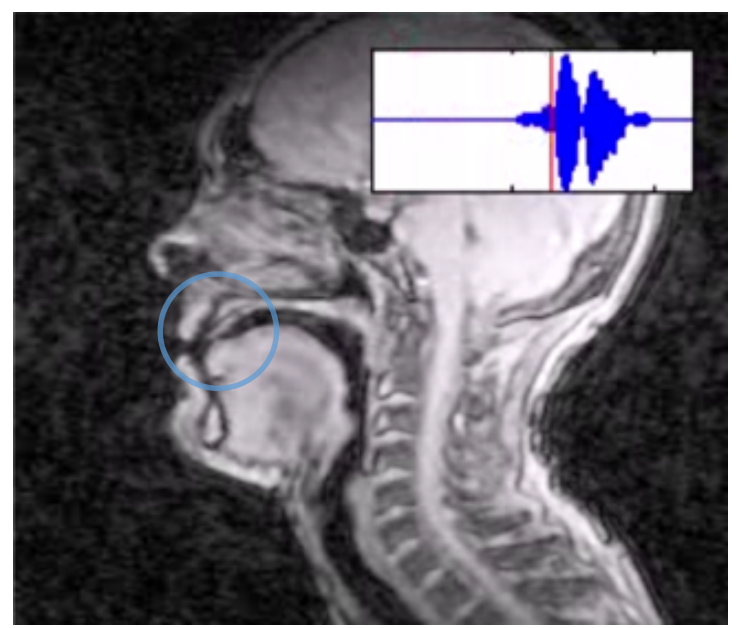

Figure 9: The MRI image of the production of [s]. 


\subsubsection{Acoustic explanation}

Fricatives are acoustically characterized by high frequency energy, because frication is generated at the constriction location in the oral cavity, not at the glottis, and as such the resonance cavity is much shorter for fricatives for than for vowels. The high acoustic frequency of fricatives is illustrated in Figure 10. This high frequency energy can be mapped onto small images due to the relationship expressed by Equation (2). We should note, however, that frication can be very intense and noisy, which may also impact on the perception of size. This ambiguous status—high in frequency but noisy and intense-may explain why the previous literature on sound symbolic values of fricatives shows ambiguous results.

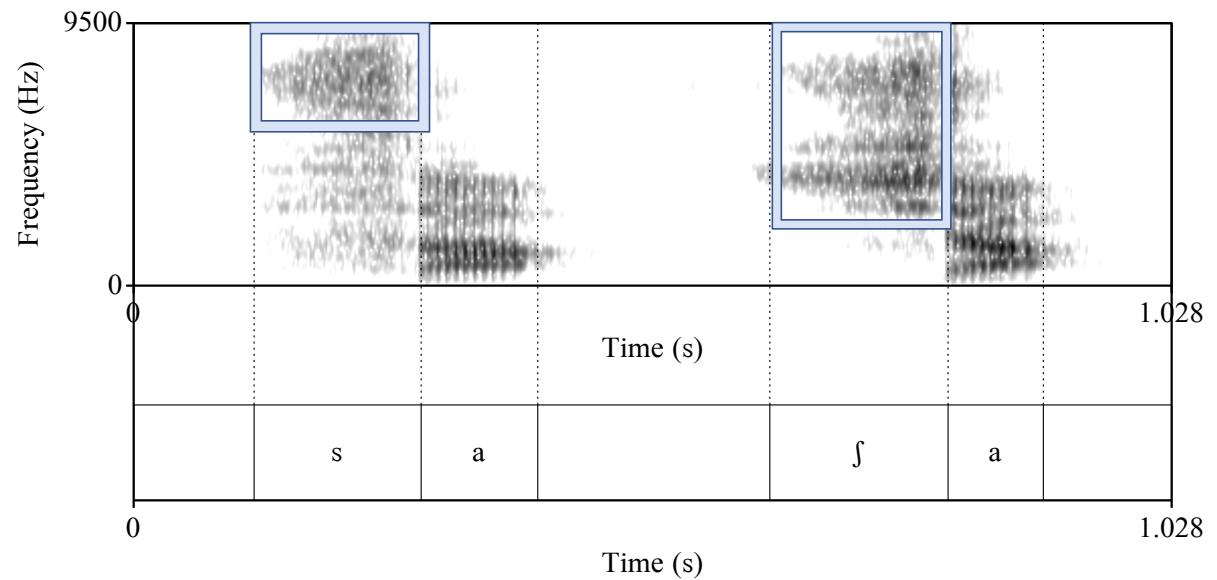

Figure 10: Spectrograms of [sa] and [ $\mathrm{sa}]$.

\subsection{Nasals are large}

\subsubsection{Observation}

Berlin (2006) observes that nasal consonants (such as [m] and [n]) are cross-linguistically overrepresented in the names of tinamou compared to those of rails, the former of which is bigger. To quote him, "nasals are consonants with a particularly low acoustic frequency and should connote slow, round, plump, fat, soft, squat, heavy creatures such as the tinamou" (p.34). See also Lapolla (1994), who argue that [m], a labial nasal consonant, is particularly associated with large images. 
467

468

\subsubsection{Articulatory explanation}

The reason why nasals may be associated with large images may be because the nasal cavity, which is responsible for creating the salient acoustic cues for nasals, is long.

\subsubsection{Acoustic explanation}

As Berlin notes, the images that are associated with nasals can be due to low frequency energy of these consonants, which are illustrated in Figure 11, the spectrograms of [m], [n] and [n]. All nasal consonants have low frequency energy, because resonance occurs in the nasal cavity, which is long.

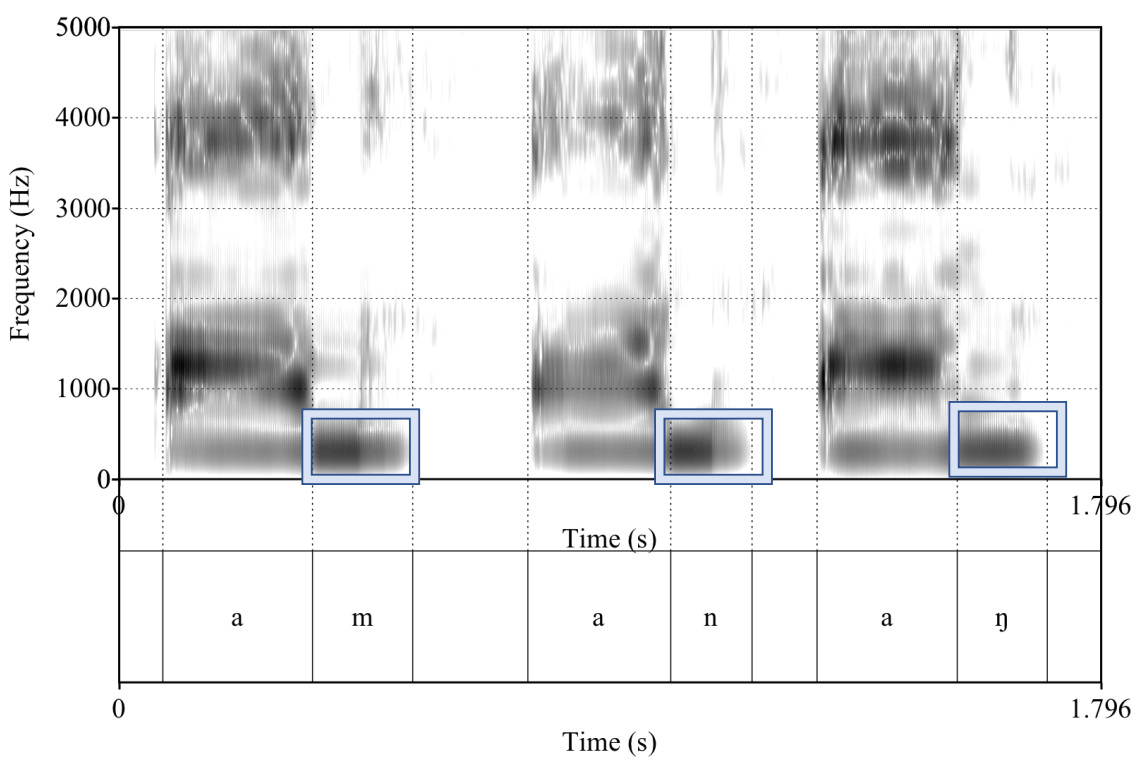

Figure 11: The spectrograms of nasals. 


\section{Consonants: non-size-related symbolism}

\subsection{Voiceless obstruents are angular, voiced consonants are round}

\subsubsection{Observation}

In the classic takete-maluma effect (Köhler 1947), [t] and [k] are associated with an angular object, whereas [m] and [1] are associated with a round object. Kawahara and Shinohara (2012) show that voiceless obstruents (e.g. [t, $\mathrm{k}, \mathrm{s}, \mathrm{t} f]$ ) in general tend to be associated with angular figures, whereas voiced sonorants (e.g. [m, l, r, w]) tend to be associated with round figures by English speakers (see also Nielsen and Rendall 2011 for a similar finding). In addition, some studies demonstrate that ¿voiced stops are judged to be more round than voiceless stops (D'Onofrio 2014, Ramachandran and Hubbard 2001). Sidhu et al. (2021) show that these tendencies may generally hold among existing words in English as well. Also possibly related is the observation that voiceless obstruents tend to be used more frequently in male names than in female names, and voiced sonorants tend to be used more frequently in female names than in male names (Sidhu and Pexman 2019). See Lindauer (1990) and Sidhu et al. (2019) for other meanings that can be associated with these two classes of sounds, which seem to be generally compatible with the notion of angularity (e.g. "unfriendly" and "aggressive") and roundness (e.g. "friendly" and "peaceful”).

\subsubsection{Articulatory explanation}

As far as I am aware of, there is nothing in the articulation of voiceless obstruents that is angular; neither is it clear whether any articulatory aspects of voiced consonants can be associated with round images.

\subsubsection{Acoustic explanation}

Kawahara and Shinohara (2012) conjectured that this sound-symbolic connection between voiceless obstruents and angular shapes derives from abrupt amplitude modulations during the burst and frication of these sounds, typical acoustic characteristics of voiceless obstruents (see also Ju- 
rafsky 2014 and Nobile 2015 for similar proposals). Aperiodic noise resulting from the rise of intraoral airpressure—defining features of obstruent—look, literally speaking, spiky and angular on waveforms, as shown in Figure 12 (a) and (b). On the other hand, periodic energies of sonorants, reflecting regular vocal fold vibrations, look round on waveforms, as in Figure 12 (c) and (d). These acoustic characteristics can be projected onto the perception of different types of shapes. Voiced stops, as long as they are accompanied by vocal fold vibration (see $\$ 5.2 .3$ ), also exhibit roundlooking periodic energy. See also Lacey et al. (2020) for an array of other acoustic parameters which can affect round/angular judgment patterns.

(a) $[\mathrm{t}]$

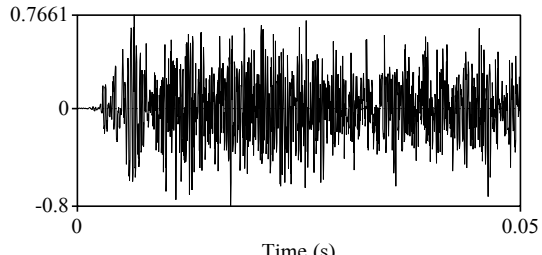

(c) $[\mathrm{n}]$

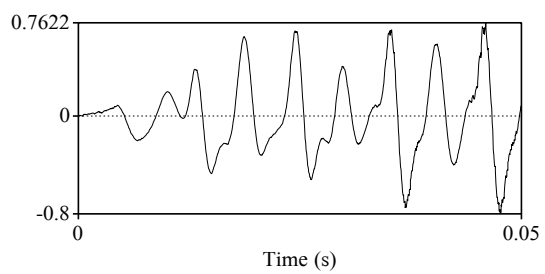

(b) $[\mathrm{s}]$

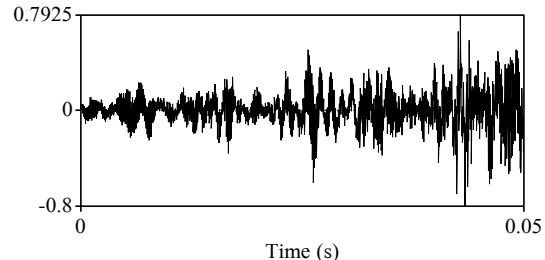

(d) $[\mathrm{w}]$

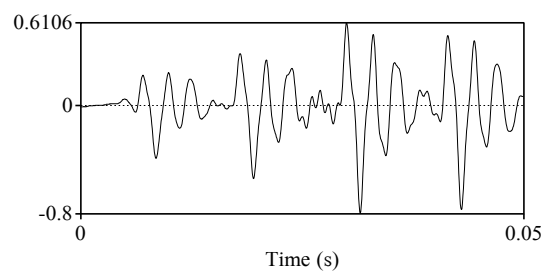

Figure 12: The waveforms of $[\mathrm{t}],[\mathrm{s}],[\mathrm{n}]$ and $[\mathrm{w}]$. These graphs track airpressure changes that are generated by these sounds. These figures are adapted from Kawahara (2017).

Particularly telling in this context is a study by Silva and Bellini-Leite (2019), who demonstrate that we observe similar sound symbolic effects when listeners are presented with sine-wave analogues of takete- and maluma-like speech. For such non-speech analogues, there are no articulatory actions that listeners can recover from the stimuli. Thus, this sort of experiment supports the view that at least some sound symbolic patterns can be triggered by acoustic properties alone. See Diehl et al. (2004) for a review of similar experiments which deploy non-speech analogues in other branches of phonetic research. 


\subsection{Labial consonants are baby-like}

\subsubsection{Observation}

Kumagai and Kawahara (2020) find that Japanese speakers prefer to use labial consonants (such as [p] and [m]) when they are asked to come up with new diaper names, in comparison to when they are asked to name new adult cosmetics, suggesting that labials may be associated with the image of cuteness. Kumagai (2019) indeed show that Japanese speakers judge labial consonants, especially [p], to be cute. Uno et al. (2020) demonstrate that labial consonants are underrepresented in evil characters' names in English Disney characters, and that they are overrepresented in the fairy type Japanese Pokémon characters. Both Japanese speakers and English speakers are sensitive to the connection between labiality and the cute fairy type Pokémon characters (Kawahara and Kumagai 2019; Kawahara et al. 2021).

\subsubsection{Articulatory explanation}

Kumagai and Kawahara (2020) hypothesize that since labial consonants are acquired at an early stage of language acquisition, observed both in babbling and early speech (Jakobson 1941; MacNeilage et al. 1997), they are associated with images of babies, and possibly by extension, the image of cuteness and smallness. See Jakobson (1971) for a related idea.

\subsubsection{Acoustic explanation}

There appears to be nothing in the acoustics of labial consonants that relate to the notions of babies or cuteness. Labial consonants are characterized by bursts with low frequency energy as well as lowering of formant frequency in surrounding vowels (Stevens and Blumstein 1981); therefore, the Frequency Code, via Equation (2), predicts that labial consonants should be judged to be larger than other types of consonants (see Lapolla 1994 for some supporting evidence) ${ }^{11}$ Thus labial consonants may have ambivalent sound symbolic values - their acoustics would lead to large images

\footnotetext{
${ }^{11}$ Berlin (2006) reports that labial consonants are more likely to be used for the names of tapir than those of squirrel, the former of which is larger, but this comparison was not statistically significant.
} 
whereas their phonological status—-how early they are acquired—may evoke small images.

\subsection{Labial consonants are round}

\subsubsection{Observation}

In the bouba-kiki effect, [b] is associated with round images (Ramachandran and Hubbard 2001). D'Onofrio (2014) and Kawahara (2021) show that labial stops in general may be associated with round images. Sidhu et al.(2021) show that actual English words that are related to roundness tend to contain labial consonants as well. See Bremner et al. (2013) and Styles and Gawne (2017) for cross-linguistic perspectives on these sound symbolic connections.

\subsubsection{Articulatory explanation}

It is conceivable that lip gestures of labial consonants are mapped onto round images, although for labial stops and nasals $(=[\mathrm{b}, \mathrm{p}, \mathrm{m}])$, lips are completely closed with each other, so that there is no literal sense in which lips are rounded for these consonants. Lip rounding gesture is evident, for example, for $[\mathrm{w}]$ and a bilabial fricative $[\phi]$.

\subsubsection{Acoustic explanation}

There is nothing in the acoustics of labial consonants that can be related to the notion of roundedness. As discussed in $\$ 6.2 .3$, labials are characterized by low acoustic energy, but there is no clear connection between low frequency energy and the notion of roundedness.

\subsection{Nasals=breast}

\subsubsection{Observation}

Several cross-linguistic studies of basic vocabularies have shown that words denoting breasts often contain nasal consonants, especially [m] (Blasi et al. 2016; Johansson et al. 2020b). 


\subsubsection{Articulatory explanation}

It is not hard to imagine that this association arises from the fact that the action of sucking breast milk resembles the articulation of nasal consonants. While sucking milk, the oral cavity (i.e. the mouth) is sealed, and infants need to breathe through the nose. During the articulation of nasal consonants, the oral cavity is closed, and the air goes through the nasal cavity. Indeed, [m] may as well be the only sound that can be easily produced while sucking breast milk.

\subsubsection{Acoustic explanation}

There is nothing in the acoustics of nasals that can be related to the notion of breasts.

\subsection{Sibilants $=f l y$}

\subsubsection{Observation}

Socrates in Cratylus suggests that $[\mathrm{s}]$ and $[\mathrm{z}]$ are suited for words that represent wind and vibration, because they involve strong breath. Likewise, the Upanishads suggests that " $[\mathrm{t}]$ he mute consonants represent the earth, the sibilants the sky, the vowels heaven. The mute consonants represent fire, the sibilants air, the vowels the sun" (Aitareya Aranyaka III.2.6.2.) ${ }^{12}$ Kawahara et al. (2020) and Kawahara et al. (2021) show that Japanese and English speakers tend to associate nonce names that contain sibilants with the flying type of Pokémon characters. Paraise et al. (2014) point out that high frequency sounds, of which sibilants are typical examples, tend to be associated with the notion of elevation.

\subsubsection{Articulatory explanation}

This sound symbolic association may be grounded in the fact that the production of sibilants involves a large amount of oral airflow compared to the other types of sounds, as Socrates already notes when he talks about "strong breath." Figure 13 shows the measurements of nasal and oral

12 https://en.wikipedia.org/wiki/Sound_symbolism\#Upanishads 
airflow obtained by Mielke (2011) using nasometer. We observe that voiceless fricatives, including sibilants, have large amount of oral airflow.

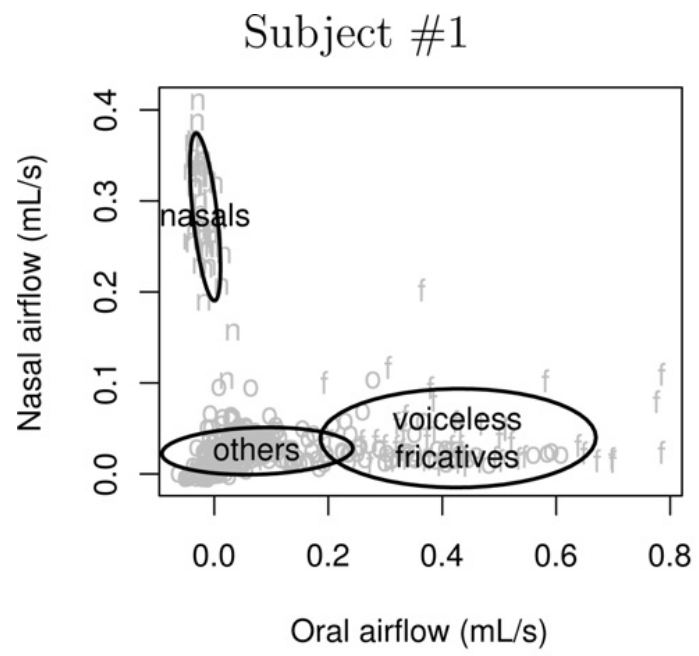

Figure 13: The nasal and oral airflow of different consonants.

\subsubsection{Acoustic explanation}

Sibilants have energy concentration in high frequency region because of their very small resonance cavities ( 5.3 .3 ). It is possible to assume that this high frequency energy can be iconically mapped onto the notion of sky or elevation, assuming that listers have some sort of representations that are similar to spectrograms; i.e. high frequency energy of frication noise appears "at the top" of a spectrogram. These semantic meanings can then be extended to the notion of flying.

\section{Conclusion}

The goal of this review was not to establish a particular theory of sound symbolism, but instead was to lay out the possible phonetic underpinnings of major sound symbolic patterns. I hope that some themes have emerged from the current discussion. A first theme is that it is plausible to suspect that phonetic considerations, either articulatory or acoustic, do play a role in shaping at least some of the systematic sound-meaning correspondence patterns found in natural languages, 
as per Socrates, Jespersen, Sapir and many subsequent scholars. From this it follows that the research on systematicity should be informed by careful phonetic considerations, as John Ohala envisioned several decades ago (Ohala 1983b).

Second, it seems plausible, at least to me, that both articulatory and acoustic considerations need to be taken into consideration (cf. the discussion in $\$ 1.2$ ). On the one hand, the association between angularity and voiceless obstruents may make better sense from an acoustic perspective (\$6.1); on the other hand, the association between roundness and rounded vowels is more straightforward to explain in terms of articulation (\$4.1). These results imply that even the most general theory, the Frequency Code $(\$ 2)$, does not cover the whole spectrum of sound symbolic patterns.

Moreover, it is very likely that multiple principles, some of them being phonetic and others being non-phonetic, must work in tandem with one another to give rise to the various systematic sound-meaning correspondences observed in human languages (Johansson et al.2020b; Sidhu and Pexman 2018). To the extent that multiple principles are at work, it predicts that some segments can have ambivalent—and sometimes conflicting-sound symbolic values. Take the case of labials, for example. The Frequency Code predicts that they should be associated with large images; on the other hand, their status as appearing in early speech and babbling may lead them to be associated with the image of babies, and possibly by extension, smallness ( 6.2 .3 . This is an intriguing prediction that a phonetically-based theory of sound symbolism makes, which is under-addressed in previous literature. To conclude, exploring how phonetic characteristics of our speech are mapped onto our sound symbolic knowledge, possibly by interacting with non-phonetic principles, should continue to be an exciting topic of future research.

\section{Declarations}

\section{Funding}

This research is supported by the JSPS grants \#17K13448 and \#20H05617. 


\section{Open Practices Statement}

This paper is a review article, and as such there is no new data.

\section{Conflicts of interest/Competing interests}

The author declares no conflicts of interest or competing interests.

\section{Ethics approval}

NA

\section{Consent to participate}

NA

\section{Consent for publication}

NA

\section{Availability of data and materials}

NA

\section{Code availability}

NA

\section{References}

Ahlner, F. and Zlatev, J. (2010). Cross-modal iconicity: A cognitive semiotic approach to sound symbolism. Sign Sytems Studies, 38(1/4):298-348.

Akita, K. (2005-2010). Bibliograhies of sound-symbolic phenomena. Ms. University of Tokyo. https://sites.google.com/site/akitambo/Home/biblio/bibb.

Alderete, J. and Kochetov, A. (2017). Integrating sound symbolism with core grammar: The case of expressive palatalization. Language, 93:731-766.

Archangeli, D. and Pulleyblank, D. (1994). Grounded Phonology. MIT Press, Cambridge.

Asano, M. and Yokosawa, K. (2010). Synesthetic colors are elicited by sound quality in Japanese synesthetes. Consciousness and Cognition, 20(4):1816-1823.

Bergen, B. K. (2004). The psychological reality of phonaesthemes. Language, 80:290-311.

Berlin, B. (2006). The first congress of ethonozoological nomenclature. Journal of Royal Anthropological Institution, 12:23-44.

Blasi, D. E., Wichman, S., Hammarström, H., Stadler, P. F., and Christianson, M. H. (2016). Sound-meaning association biases evidenced across thousands of languages. Proceedings of National Academy of Sciences, 113(39):10818-10823. 
Bremner, A. J., Caparos, S., Davidoff, J., de Fockert, J., Linnell, K. J., and Spence, C. (2013). "Bouba" and "Kiki" in Namibia? A remote culture make similar shape-sound matches, but different shape-taste matches to Westerners. Cognition, 126:165-172.

Browman, C. and Goldstein, L. (1986). Towards an articulatory phonology. Phonology Yearbook, 3:219-252.

Chodroff, E. and Wilson, C. (2014). Burst spectrum as a cue for the stop voicing contrast in American English. Journal of the Acoustical Society of America, 136(5):2762-2772.

Chomsky, N. and Halle, M. (1968). The Sound Pattern of English. Harper and Row, New York.

Coulter, S. K. and Coulter, R. A. (2010). Small sounds, big deals: Phonetic symbolism effects in pricing. Journal of Consumer Research, 37(2):315-328.

Diehl, R., Lotto, A. J., and Holt, L. L. (2004). Speech perception. Annual Review of Psychology, 55:149-179.

Diffloth, G. (1994). i: big, a: small. In Hinton, L., Nichols, J., and Ohala, J., editors, Sound Symbolism, pages 107-114. Cambridge University Press, Cambridge.

Dingemanse, M., Blasi, D. E., Lupyan, G., Christiansen, M. H., and Monaghan, P. (2015). Arbitrariness, iconicity and systematicity in language. Trends in Cognitive Sciences, 19(10):603615.

Dingemanse, M. and Thompson, B. (2020). Playful iconicity: structural markedness underlies the relation between funniness and iconicity. Language and Cognition, 12(1):203-224.

D'Onofrio, A. (2014). Phonetic detail and dimensionality in sound-shape correspondences: Refining the bouba-kiki paradigm. Language and Speech, 57(3):367-393.

Flemming, E. (1995). Auditory Representations in Phonology. Doctoral dissertation, University of California, Los Angeles.

Fowler, C. (1986). An event approach to the study of speech perception from a direct realist perspective. Journal of Phonetics, 14:3-28.

Godoy, M. C., de Souza Filho, N. S., Marques de Souza, J. G., Alves, H., and Kawahara, S. (2020). Gotta name'em all: An experimental study on the sound symbolism of Pokémon names in Brazilian Portuguese. Journal of Psycholinguistic Research, 49:717-740.

Gussenhoven, C. (2004). The Phonology of Tone and Intonation. Cambridge University Press, Cambridge.

Hamano, S. (1998). The Sound-Symbolic System of Japanese. CSLI Publications, Stanford.

Hayes, B., Kirchner, R., and Steriade, D., editors (2004). Phonetically Based Phonology. Cambridge University Press, Cambridge.

Hayes, B. and Steriade, D. (2004). Introduction: The phonetic bases of phonological markedness. In Hayes, B., Kirchner, R., and Steriade, D., editors, Phonetically Based Phonology., pages 1-33. Cambridge University Press, Cambridge.

Houde, J. F. and Jordan, M. I. (2002). Sensorimotor adaptation of speech I: Compensation and adaptation. Journal of Speech, Language, and Hearing Research, 45:239-262.

Iwasaki, N., Vinson, D. P., and Vigiliocco, G. (2007). What do English speakers know about geragera and yota-yota? A cross-linguistic investigation of mimetic words for laughing and walking. Japanese Language Education Around the Globe, 17:53-78.

Jakobson, R. (1941). Child Language, Aphasia and Phonological Universals. Mouton, The Hague. Translated into English by A. Keiler, 1968.

Jakobson, R. (1971). Why 'mama' and 'papa'? In Phonological Studies 2nd. Vol 1 of Roman Jakobson Selected Writings, pages 538-545. Mouton, The Hague/Paris. 
Jang, H. (2021). How cute do I sound to you?: Gender and age effects in the use and evaluation of Korean baby-talk register, Aegyo. Language Sciences, 83.

Jespersen, O. (1922). Symbolic value of the vowel $i$. In Linguistica: Selected Papers in English, French and German, volume 1, pages 283-303. Levin and Munksgaard, Copenhagen.

Johansson, N., Anikin, A., and Aseyev, N. (2020a). Color sound symbolism in natural languages. Language and Cognition, 12(1):56-83.

Johansson, N. E., Anikin, A., Carling, G., and Holmer, A. (2020b). The typology of sound symbolism: Defining macro-concepts via their semantic and phonetic features. Linguistic Typology, 24(2):253-310.

Johnson, K. (2020). In memoriam John J. Ohala (1941-2020). Journal of International Phonetic Association, 50(3):452-455.

Jurafsky, D. (2014). The Language of Food: A Linguist Reads the Menu. W. W. Norton \& Company, New York.

Kawahara, S. (2017). Introducing Phonetics through Sound Symbolism. Hitsuzi Syobo, Tokyo.

Kawahara, S. (2020a). Sound symbolism and theoretical phonology. Language and Linguistic Compass, 14(8):e12372.

Kawahara, S. (2020b). A wug-shaped curve in sound symbolism: The case of Japanese Pokémon names. Phonology, 37(3):383-418.

Kawahara, S. (2021). Pokémon meets psychology and linguistics: Experimental and theoretical exploration of the bouba-kiki effect. Phonological Studies, 24:77-84.

Kawahara, S. and Breiss, C. (2021). Exploring the nature of cumulativity in sound symbolism: Experimental studies of Pokémonastics with English speakers. Laboratory Phonology, 12(1).

Kawahara, S., Godoy, M. C., and Kumagai, G. (2020). Do sibilants fly? Evidence from a sound symbolic pattern in Pokémon names. Open Linguistics, 6(1):386-400.

Kawahara, S., Godoy, M. C., and Kumagai, G. (2021). English speakers can infer Pokémon types based on sound symbolism. Frontiers in Psychology, 12:648948.

Kawahara, S. and Kumagai, G. (2019). Inferring Pokémon types using sound symbolism: The effects of voicing and labiality. Journal of the Phonetic Society of Japan, 23(2):111-116.

Kawahara, S. and Kumagai, G. (2021). What voiced obstruents symbolically represent in Japanese: Evidence from the Pokémon universe. Journal of Japanese Linguistics, 37(1):3-24.

Kawahara, S. and Moore, J. (2021). How to express evolution in English Pokémon names. Linguistics, 59(3):577-607.

Kawahara, S. and Shinohara, K. (2012). A tripartite trans-modal relationship between sounds, shapes and emotions: A case of abrupt modulation. Proceedings of CogSci, 2012:569-574.

Kingston, J. and Diehl, R. (1994). Phonetic knowledge. Language, 70:419-454.

Knoeferle, K., Li, J., Maggioni, E., and Spence, C. (2017). What drives sound symbolism? Different acoustic cues underlie sound-size and sound-shape mappings. Scientific Reports, 7.

Köhler, W. (1947). Gestalt Psychology: An Introduction to New Concepts in Modern Psychology. Liveright, New York.

Kumagai, G. (2019). A sound-symbolic alternation to express cuteness and the orthographic Lyman's Law in Japanese. Journal of Japanese Linguistics, 35(1):39-74.

Kumagai, G. and Kawahara, S. (2019). Effects of vowels and voiced obstruents on Pokémon names: Experimental and theoretical approaches [in Japanese]. Journal of the Linguistic Society of Japan, 155:65-99.

Kumagai, G. and Kawahara, S. (2020). How abstract is sound symbolism? Labiality and diaper 
names in Japanese [in Japanese]. Journal of the Linguistic Society of Japan, 157:149-161.

Lacey, S., Jamal, Y., List, S. M., McComick, K., Sathian, K., and Nygaard, L. C. (2020). Stimulus parameters underlying sound symbolic mapping of auditory psedowords to visual shapes. Cognitive Science, page e12883.

Lapolla, R. J. (1994). An experimental investigation into phonetic symbolism as it relates to Mandarin Chinese. In Sound Symbolism, pages 130-147. Cambridge University Press, Cambridge.

Li, F., Munson, B., Edwards, J., Yoneyama, K., and Hall, K. (2011). Language specificity in the perception of voiceless sibilant fricatives in japanese and english: Implications for crosslanguage differences in speech-sound development. journal of the Acoustical Society of America, 129(2):999-1011.

Liberman, A. M. and Mattingly, I. G. (1985). The motor theory of speech perception revised. Cognition, 21:1-36.

Lindauer, S. M. (1990). The meanings of the physiognomic stimuli taketa and maluma. Bulletin of Psychonomic Society, 28(1):47-50.

MacNeilage, P. F., Davis, B. L., and Matyear, C. L. (1997). Babbling and first words: Phonetic similarities and differences. Speech Communication, 22(2-3):269-277.

Mielke, J. (2011). A phonetically based metric of sound similarity. Lingua, 122(2):145-163.

Mok, P. P. K., Li, G., Li, J. J., Ng, H. T. Y., and Cheung, H. (2019). Cross-modal association between vowels and colours: A cross-linguistic perspective. Journal of the Acoustical Society of America, 145(4):2265-2276.

Moos, A., Smith, R., Miller, S. R., and Simmons, D. R. (2014). Cross-modal associations in synaesthesia: Vowel colours in the ear of the beholder. i-Perception, 5(2):132-142.

Newman, S. (1933). Further experiments on phonetic symbolism. American Journal of Psychology, 45:53-75.

Nielsen, A. K. S. and Rendall, D. (2011). The sound of round: Evaluating the sound-symbolic role of consonants in the classic takete-maluma phenomenon. Canadian Journal of Experimental Psychology, 65:115-124.

Nobile, L. (2015). Phonemes as images: An experimental inquiry into shape-sound symbolism applied to the distinctive features of French. In Hiraga, M., Herlofsky, W., Shinohara, K., and Akita, K., editors, Iconicity: East meets west, pages 71-91. John Benjamins, Amsterdam.

Ohala, J. (1983a). The origin of sound patterns in vocal tract constraints. In MacNeilage, P., editor, The Production of Speech, pages 189-216. Springer-Verlag, New York.

Ohala, J. (1983b). The phonological end justifies any means. In Hattori, S. and Inoue, K., editors, Proceedings of the 13th International Congress of Linguists, pages 232-243. Sanseido, Tokyo.

Ohala, J. (1984). An ethological perspective on common cross-language utilization of f0 of voice. Phonetica, 41:1-16.

Ohala, J. (1994). The frequency code underlies the sound symbolic use of voice pitch. In Hinton, L., Nichols, J., and Ohala, J., editors, Sound Symbolism, pages 325-347. Cambridge University Press, Cambridge.

Paraise, C. V., Knorre, K., and Ernst, M. O. (2014). Natural auditory scene statistics shapes human spatial hearing. Proceedings of National Academy of Sciences, 111(16):6104-6108.

Parker, S. (2008). Sound level protrusions as physical correlates of sonority. Journal of Phonetics, 36:55-90.

Perlman, M. and Lupyan, G. (2018). The potential for iconicity in vocalization. Scientific Reports, 8(1). 
Proctor, M. I., Shadle, C. H., and Iskarous, K. (2010). Pharyngeal articulation differences in voiced and voiceless fricatives. Journal of the Acoustical Society of America, 127(3):1507-1518.

Ramachandran, V. S. and Hubbard, E. M. (2001). Synesthesia-a window into perception, thought, and language. Journal of Consciousness Studies, 8(12):3-34.

Saji, N., Akita, K., Kantartzis, K., Kita, S., and Imai, M. (2019). Cross-linguistically shared and language-specific sound symbolism in novel words elicited by locomotion videos in Japanese and English. PloS ONE, 14(7):e0218707, doi.org/10.1371/journal.pone.0218707.

Sapir, E. (1929). A study in phonetic symbolism. Journal of Experimental Psychology, 12:225239.

Saussure, F. (1916). Cours de linguistique générale. Payot, Paris.

Shinohara, K. and Kawahara, S. (2009). A cross-linguistic study of sound symbolism: Images evoked by voicing. Proceedings of the 26th Annual Meeting of Japanese Cognitive Science Society.

Shinohara, K. and Kawahara, S. (2016). A cross-linguistic study of sound symbolism: The images of size. In Proceedings of the Thirty Sixth Annual Meeting of the Berkeley Linguistics Society., pages 396-410. Berkeley Linguistics Society, Berkeley.

Sidhu, D. and Pexman, P. M. (2018). Five mechanisms of sound symbolic association. Psychonomic Bulletin \& Review, 25(5):1619-1643.

Sidhu, D. and Pexman, P. M. (2019). The sound symbolism of names. Current Directions in Psychological Science, 28(4):398-402.

Sidhu, D. M., Deschamps, K., Bourdage, J. S., and Pexman, P. M. (2019). Does the name say it all? Investigating phoneme-personality sound symbolism in first names. Journal of Experimental Psychology: General, 148(9):1595-1614.

Sidhu, D. M., Westbury, C., Hollis, G., and Pexman, P. M. (2021). Sound symbolism shapes the English language: The maluma/takete effect in English nouns. Psychonomic Bulletin \& Review. Silva, D. M. R. and Bellini-Leite, S. C. (2019). Cross-modal correspondences in sine wave: Speech versus non-speech modes. Attention, Perception \& Psychophysics, 82:944-953.

Stevens, K. (1989). On the quantal nature of speech. Journal of Phonetics, 17:3-45.

Stevens, K. and Blumstein, S. (1981). The search for invariant acoustic correlates of phonetic features. In Eimas, P. and Miller, J. D., editors, Perspectives on the Study of Speech, pages 1-38. Earlbaum, New Jersey.

Styles, S. J. and Gawne, L. (2017). When does maluma/takete fail? Two key failures and a metaanalysis suggest that phonology and phonotactics matter. $i$-Perception, 8(4):1-17.

Ultan, R. (1978). Size-sound symbolism. In Greenberg, J., editor, Universals of Human Language II: Phonology, pages 525-568. Stanford University Press, Stanford.

Uno, R., Shinohara, K., Hosokawa, Y., Ataumi, N., Kumagai, G., and Kawahara, S. (2020). What's in a villain's name? Sound symbolic values of voiced obstruents and bilabial consonants. Review of Cognitive Linguistics, 18(2):428-457.

Westbury, C., Hollis, G., Sidhu, D. M., and Pexman, P. M. (2018). Weighting up the evidence for sound symbolism: Distributional properties predict cue strength. Journal of Memory and Language, 99:122-150.

Whalen, D. H. and Levitt, A. G. (1995). The universality of intrinsic F0 of vowels. Journal of Phonetics, 23:349-366.

Winter, B. and Perlman, M. (2021a). Iconicity ratings really do measure iconicity, and they open a new window onto the nature of language. Linguistic Vanguard. 
${ }_{828}$ Winter, B. and Perlman, M. (2021b). Size sound symbolism in the English lexicon. Glossa. 829 Zsiga, E. (2020). The phonology/phonetics interface. Edinburgh University Press, Edinburgh. 